This item was submitted to Loughborough's Research Repository by the author.

Items in Figshare are protected by copyright, with all rights reserved, unless otherwise indicated.

\title{
Examination of changes in annual maximum gage height in the continental United States using quantile regression
}

PLEASE CITE THE PUBLISHED VERSION

https://doi.org/10.1061/(ASCE)HE.1943-5584.0001620

\section{PUBLISHER}

(C) American Society of Civil Engineers

\section{VERSION}

AM (Accepted Manuscript)

\section{PUBLISHER STATEMENT}

This work is made available according to the conditions of the Creative Commons Attribution-NonCommercialNoDerivatives 4.0 International (CC BY-NC-ND 4.0) licence. Full details of this licence are available at: https://creativecommons.org/licenses/by-nc-nd/4.0/

\section{LICENCE}

CC BY-NC-ND 4.0

\section{REPOSITORY RECORD}

Villarini, Gabriele, and Louise Slater. 2019. "Examination of Changes in Annual Maximum Gage Height in the Continental United States Using Quantile Regression”. figshare. https://hdl.handle.net/2134/26399. 
Technical note

4 \\ Examination of Changes in Annual Maximum Gage Height in the Continental United States Using Quantile Regression
}

\author{
GABRIELE VILLARINI $^{1}$ AND LOUISE J. SLATER ${ }^{2}$ \\ ${ }^{1}$ IIHR-Hydroscience \& Engineering, The University of Iowa, Iowa City, Iowa, USA. \\ ${ }^{2}$ Department of Geography, Loughborough University, Loughborough, UK. \\ Manuscript submitted to \\ Journal of Hydrologic Engineering \\ 6 February 2017
}

Revised April 2017

Accepted 30 August 2017

Corresponding author address:

Gabriele Villarini, IIHR-Hydroscience \& Engineering, The University of Iowa, 306 C. Maxwell Stanley Hydraulics Laboratory, Iowa City, 52242, Iowa, USA. E-mail: gabrielevillarini@uiowa.edu. Tel.: (319) 384-0596

\begin{abstract}
This study focuses on the detection of temporal changes in annual maximum gage height (GH) across the continental United States and their relationship to changes in short- and long-term precipitation. Analyses are based on 1805 U.S. Geological Survey records over the 1985-2015 period and are performed using quantile regression. Trends were significant only at a limited number of sites, with a higher number of detections at the tails of the distribution. Overall, we found only weak evidence that the annual maximum GH records have been changing over the continental United States during the past 30 years, possibly due to a weak signal of change, large variability, and limited record length. In addition to trend detection, we also assessed to what extent these changes can be attributed to storm total rainfall and long-term precipitation. Our findings indicate that temporal changes in GH maxima are largely driven by storm total rainfall across large areas of the continental United States (east of the $100^{\text {th }}$ meridian, U.S. West Coast). Long-term precipitation accumulation, on the other hand, is a strong flood predictor in regions where snowmelt is an important flood generating mechanism (e.g., northern Great Plains, Rocky Mountains), and is overall a relatively less important predictor of extreme flood events.
\end{abstract}




\section{Introduction}

The issue of temporal changes in flooding is one that has received extensive attention in the peer-reviewed literature (consult Villarini and Slater (2017) for a recent review). Changing flood patterns and the existence of increasing or decreasing flood trends (both in terms of flood frequency and magnitude) have important implications for the design of water-related projects and flood mitigation measures, even though it is recognized that such trends cannot and should not be directly extrapolated into the future. The approach most widely used to detect changes in flooding resorts to: 1) the use of annual maximum discharge records, and 2) the application of the Mann-Kendall test to these time series. Statements about the presence of statistically significant increasing/decreasing trends are generally made as the outcome of these analyses. While this traditional approach has several advantages (e.g., it is easy to perform, standardized, and results can be compared across different areas), it can be complemented and improved upon by working with different flood-related quantities and by using other methodologies.

Most of the attention in the literature has been on annual maximum discharge data. As discussed in Slater et al. (2015) and Slater (2016), the use of discharge data for detecting changes in flood hazard is not ideal, as high flow measurements are subject to errors associated with rating curve uncertainty, and discharge trends may conceal the effect of changes in the river channel capacity on the flood hazard. To address these issues, Slater and Villarini (2016) recently focused on gage height $(\mathrm{GH})$ rather than discharge, and showed that the changes in flood risk across the continental United States were not uniform. Broadly speaking, we found that large areas of the northern (southern) United States exhibited increasing (decreasing) trends in the number of times that the flood thresholds established by the National Weather Service (NWS), in particular for action and minor flooding, were exceeded. Working with GH time series has some key advantages over discharge, since water level measurements are a more direct measure of flood hazard and are less prone to errors. Yet, little is known about the trends in the annual maximum GH records across the continental United States.

A second issue is related to the use of the Mann-Kendall test (e.g., Helsel and Hirsch 1993) to identify the presence of monotonic patterns in the time series of interest. While the MannKendall test is perfectly appropriate, it focuses on the detection of changes in the central part of the distribution of the variable of interest, and does not test for the presence of trends in different parts of the distribution (e.g., in cases where the largest annual maxima are increasing while the lowest annual maxima are decreasing; Kinsvater and Fried 2017). To examine the presence of changes in different quantiles of the distribution, quantile regression (Koenker and Basset 1978, Koenker 2005) represents a viable and well-established framework. Few studies have used quantile regression in the hydrologic literature. For instance, Allamano et al. (2009) examined the presence of temporal trends in the annual maximum discharge at 27 Swiss stream gages, and found increasing trends, in particular for large floods. Villarini et al. (2011b) found limited evidence of changes in the magnitude of flooding for the Tiber River across different quantiles once step changes were accounted for. Kormos et al. (2016) found that low flow extremes declined in numerous sites across the U.S. Pacific Northwest. Villarini et al. (2011a) focused on 
annual maximum precipitation across the central United States and found that about $10 \%$ of the rain gage records exhibited increasing trends, mostly for low-to-moderate quantiles (see also Choi et al. (2014) for analyses focused on Wisconsin). Using quantile regression, Kim and Jain (2011) found significant trends in the tail of the distribution of extreme precipitation in Korea, but not in the median.

The literature so far has largely focused on the refinement of trend detection methods to detect changes in flooding. While trend detection is useful, it remains limited if one does not attempt to understand the drivers that are responsible for the observed changes (see Merz et al. (2012) for a discussion). For instance, Slater and Villarini (2016) found that the frequency of exceedance of the NWS flood thresholds by GH can generally be described in terms of precipitation and basin wetness. Here we focus on precipitation occurring in the 10-day period prior to a GH annual maximum event ("storm precipitation") and in the 365 days prior to the storm ("basin wetness") as the key drivers of the observed changes in GH extremes, similar to Slater and Villarini (2016). Moreover, we explore the dependence of these results on the different quantiles of the GH distribution using quantile regression. The main contributions of this work are therefore the use of GH instead of discharge, the use of quantile regression instead of the more traditional Mann-Kendall test, and the attribution of the observed changes in GH to storm precipitation and basin wetness.

The research questions we focus on in this study are:

1) What trends in GH annual maxima can we detect across the continental United States?

\section{Data and Methodology}

We analyze 1805 U.S. Geological Survey (USGS) stream gages with at least 14 water years of daily GH data over the 1985-2015 period (Figure 1). These data are a subset of those used in Slater and Villarini (2016), where all of the data processing details are provided. At each site, we identify the largest daily GH value in every complete water year (defined as having at least 330 daily observations). In water years where two identical GH maxima were selected, we retain only the earliest of the two.

To explain the year-to-year variations in GH annual maxima, we compute antecedent wetness over the short term ("storm precipitation") and long term ("basin wetness") using precipitation data from the PRISM Climate Group (e.g., Daly et al. 2002; available at http://prism.oregonstate.edu). The spatial and temporal resolutions of this product are $\sim 4 \mathrm{~km}$ and daily. Basin-averaged daily values are computed using the basin boundaries from USGS Streamgage NHDPlus Version 1 Basins 2006. We use both shorter and longer precipitation accumulations to reflect the relative role that storm precipitation and overall basin wetness play for different quantiles of the GH distribution. As in Slater and Villarini (2016), storm 
precipitation is computed for each annual GH maximum at every site by aggregating the basinaveraged precipitation over the 10 days preceding and including the day of the peak; the basin wetness is computed by aggregating the precipitation over the 365-day period that preceded the storm precipitation. All 1805 sites had at least 14 annual GH maxima with antecedent storm precipitation and basin wetness values.

We detect linear trends in the GH records using quantile regression (Koenker and Basset 1978, Koenker 2005). Briefly, quantile regression can be viewed as an expansion of the ordinary least squares (OLS) approach. In OLS, the conditional mean of the response variable $Y$ is modeled with respect to one or more predictors, and the sum of the squared errors is minimized. The idea behind quantile regression is to model the conditional quantile of $Y$ in terms of predictors. For instance, in median regression, where the quantile $\tau$ is equal to 0.5 , the sum of the absolute errors is minimized. By extending this approach to other $\tau$ quantiles, we minimize an asymmetrically weighted sum of absolute errors to estimate the intercept and slope term(s). Here we focus on $\tau$ quantiles ranging from 0.05 to 0.95 with a step of 0.05 . The significance level for the slopes is set at 5\% (two-sided) and computed using bootstrap (no correction for potential autocorrelation). In terms of predictors, we use time (year of event) to detect the presence of temporal trends in the GH records, and total precipitation accumulated in a given window (10 days prior to maximum annual $\mathrm{GH}$, and 365 days prior to the 10-day window), to improve our understanding of what may have driven the inter-annual variability in different parts of the extreme GH distribution.

An extensive discussion about the theoretical framework, application and references related to quantile regression can be found in Koenker (2005). All the calculations were performed in R

\section{Results}

Analyses of temporal changes in the GH records using the Mann-Kendall test (Figure 2, bottom-right panel) indicate that just 35 (77) sites have statistically significant increasing (decreasing) trends, with the majority of the decreasing trends generally located in the southern part of the United States. As previously discussed, however, the Mann-Kendall test focuses on the central part of the conditional distribution of GH, potentially missing changes that occur at the tails. Figure 2 shows that the broad separation of increasing/decreasing trends in the northern/southern half of the continental United States is generally still detected using quantile regression. However, as shown in Figure 2 and Supplementary Figure 1, more changes are detected when we focus on low and high $\tau$ values, which suggests that the temporal changes in GH are stronger at the lower and upper tails of the distribution. Furthermore, there are areas like the U.S. Pacific Northwest where the lower quantiles of the GH distribution show increasing trends, while the higher quantiles display the opposite tendency; this discrepancy points to a narrowing of the GH distribution in the most recent years. Given the limited number of sites with statistically significant results, we applied the Walker's test and the false discovery rate test (Wilks 2006), and found that they were not field significant. The lack of a strong indication of 
statistically significant trends may be due to the weak signal, the large noise associated with the extremes, and to the limited (i.e., 30 years) record length.

Broadly speaking, these results are consistent with Slater and Villarini (2016), who found that the frequency of exceedance of NWS flood levels was not uniform with the United States, but rather characterized by a broad north/south divide. Slater and Villarini (2016), however, found a greater proportion of sites with statistically significant trends in the number of annual days above the NWS flood levels. By comparing all of these results, we find that the GH has not been increasing in magnitude over the past 30 years, but rather that there have been changes in the duration of flood level exceedance (increases or decreases depending on the location). One possible research direction moving forward is to focus on the persistence of large-scale climate conditions that are conducive to wetter/dryer periods, and to examine how these conditions may have changed over the past 30 years.

In addition to the detection of temporal changes in $\mathrm{GH}$ extremes, we use quantile regression to quantify the role played by storm precipitation and basin wetness for different parts of the GH distribution (Figure 3). Storm precipitation is identified as a statistically significant predictor of GH magnitude across large areas east of the $100^{\text {th }}$ meridian and along the U.S. West Coast (Figure 3, left panels). This is consistent with the expectation that liquid precipitation (i.e., rainfall) drives the occurrence of these flood events (e.g., Villarini 2016, Berghuijs et al. 2016). In contrast, in the northern Great Plains, the Rocky Mountains, and the north-eastern United States the flood events do not exhibit a statistically significant relationship with storm precipitation, likely because the vast majority of these events are driven by snowmelt (e.g., Berghuijs et al. 2016). Overall, the central part of the GH distribution tends to be more closely related to storm precipitation (Figure 4, top panel), possibly due to the use of a 10-day window across all sites.

The results differ when we focus on the role played by basin wetness (Figure 3, right panels; Figure 4, bottom panel). Most of the regions for which we did not find a statistically significant relationship with storm precipitation (e.g., northern Great Plains and Rocky Mountains) do present a statistically significant relationship with basin wetness. The dependence of these results on conditional quantiles is also different from the results that were found using storm precipitation as a predictor. As shown in Figure 4 (bottom panel), the number of significant sites decreases for increasing $\tau$ values; basin wetness is a significant predictor for 489 sites at $\tau=0.05$, but only for 298 sites at $\tau=0.95$. These results are consistent with Wood et al. (1990) and Smith et al. (2013), who found that the role played by antecedent soil moisture conditions diminishes as flood events become more extreme.

\section{Summary and Conclusion}

We analyzed daily GH records at 1805 USGS sites across the continental United States using quantile regression. Our focus was on the detection of trends in the annual maximum GH series, and the relationship between these maxima and precipitation accumulated in the 10 days (i.e., 
storm precipitation) and 365 days (i.e., basin wetness) prior to their occurrence. Our findings can be summarized as follows:

- The temporal changes in the United States exhibit regional differences, with the northern (southern) half pointing to increasing (decreasing) trends. These trends vary across different parts of the GH distribution, and are generally more frequently detected towards the tails of the distribution.

- Results based on the Mann-Kendall test, which focuses on the central part of the distribution, suggested a more muted signal of change. The use of quantile regression, in contrast, provides a more comprehensive perspective on the changes occurring in different parts of the distribution.

- The results from the trend detection analyses are not field significant, suggesting that when a signal of change is present, the signal may be weak or the level of noise in the data may be large, likely due to the shortness of record length.

- Storm precipitation is an important explanatory variable for the areas of the country where flood events are tied to rainfall (e.g., east of the $100^{\text {th }}$ meridian, U.S. West Coast). The role of basin wetness becomes more relevant in areas where snowmelt represents a more dominant flood generating mechanism (e.g., northern Great Plains, Rocky Mountains).

- The role of basin wetness decreases as events become more extreme, consistent with a diminished role played by antecedent soil moisture conditions for more extreme flooding.

The examination of changes in annual maximum precipitation and annual precipitation (Supplementary Figure 2) indicates that the broad north-south divide found in GH is equally reflected in the precipitation records, with local differences likely driven by changes in land surface / land cover and water management. Future studies could take our attribution results further by examining the role of human-induced climate change on precipitation and consequently on flooding across the United States (e.g., van der Wiel et al., 2016; Wang et al., 2016).

Acknowledgments. We are extremely grateful to the USGS for collecting and providing us with the gage height data. This material is based upon work supported by the Broad Agency Announcement Program and the Engineer Research and Development Center-Cold Regions Research and Engineering Laboratory under Contract W913E5-16-C-0002, National Science Foundation under CAREER Grant AGS-1349827, IIHR-Hydroscience and Engineering, and the Iowa Flood Center. We acknowledge comments and suggestions by two anonymous reviewers and the editors. 


\section{References}

Allamano, P., P. Claps, and F. Laio (2009), Global warming increases flood risk in mountainous areas, Geophysical Research Letters, 36, L24404, doi:10.1029/2009GL041395.

Berghuijs, W.R., R.A. Woods, C.J. Hutton, and M. Sivapalan (2016), Dominant flood generating mechanisms across the United States, Geophysical Research Letters, 43, 4382-4390, doi:10.1002/2016GL068070.

Choi, W., R. Tareghian, J. Choi, and C.-S Hwang (2014), Geographically heterogeneous temporal trends of extreme precipitation in Wisconsin, USA during 1950-2006, International Journal of Climatology, 34, 2841-2852.

Daly, C., W.P. Gibson, G.H. Taylor, G.L. Johnson, P. Pasteris (2002), A knowledge-based approach to the statistical mapping of climate, Climate Research, 22, 99-113.

Helsel, D.R., and R.M. Hirsch (1993), Statistical Methods in Water Resources, Elsevier.

Kim, J.-S., and S. Jain (2011), Precipitation trends over the Korean peninsula: Typhoon-induced changes and a typology for characterizing climate-related risk, Environmental Research Letters, 6, 1-8.

Kinsvater, P., and R. Fried (2017), Conditional heavy-tail behavior with applications to precipitation and river flow extremes, Stochastic Environmental Research and Risk Assessment, doi:10.1007/s00477016-1345-0, 2017.

Koenker, R. (2005), Quantile Regression, Cambridge University Press, New York.

Koenker, R. (2016), quantreg: Quantile Regression. R package version 5.29. https://CRAN.Rproject.org/package=quantreg.

Koenker, R., and G.W. Basset (1978), Regression quantiles, Econometrica, 46, 33-50.

Kormos, P.R., C.H. Luce, S.J. Wenger, and W.R. Berghuijs (2016), Trends and sensitivities of low streamflow extremes to discharge timing and magnitude in Pacific Northwest mountain streams, Water Resources Research, 52, 4990-5007.

Merz, B., S. Vorogushy, S. Uhlemann, J. Delgado, and Y. Hundecha (2012), More efforts and scientific rigour are needed to attribute trends in flood time series, Hydrology and Earth System Sciences, 16, 1379-1387.

R Core Team (2016), R: A language and environment for statistical computing. R Foundation for Statistical Computing, Vienna, Austria. URL https://www.R-project.org/.

Slater, L.J., and G. Villarini (2016), Recent trends in US flood risk, Geophysical Research Letters, 43(24), 12428-12436.

Slater L.J. (2016), To what extent have changes in channel capacity contributed to flood hazard trends in England and Wales? Earth Surface Processes and Landforms, 41, 1115-1128.

Slater, L.J., M.B. Singer, and J.W. Kirchner (2015), Hydrologic versus geomorphic drivers of trends in flood hazard, Geophysical Research Letters, 42,370-376.

Smith, J.A., M.L. Baeck, G. Villarini, D.B. Wright, and W.F. Krajewski (2013), Extreme flood response: The June 2008 flooding in Iowa, Journal of Hydrometeorology, 14(6), 1810-1825.

van der Wiel, K., S. B. Kapnick, G. J. van Oldenborgh, K. Whan, S. Philip, G. A. Vecchi, R. K. Singh, J. Arrighi, and H. Cullen (2017), Rapid attribution of the August 2016 flood-inducing extreme precipitation in south Louisiana to climate change, Hydrol. Earth Syst. Sci., 21, 897-921.

Villarini, G. (2016), On the seasonality of flooding across the continental United States, Advances in Water Resources, 87, 80-91.

Villarini, G., and L.J. Slater (2017), Climatology of Flooding in the United States, in Oxford Research Encyclopedia of Natural Hazard Science, DOI: 10.1093/acrefore/9780199389407.013.123. 
Villarini, G., J.A. Smith, M.L. Baeck, R. Vitolo, D.B. Stephenson, and W.F. Krajewski (2011a), On the frequency of heavy rainfall for the Midwest of the United States, Journal of Hydrology, 400(1-2), 103-120.

Villarini, G., J.A. Smith, F. Napolitano, and M.L. Baeck (2011b), Hydrometeorological analyses of the December 2008 flood in Rome, Hydrological Sciences Journal, 56(7), 1150-1165.

Wang, S. Y. S., L. Zhao, and R. R. Gillies (2016), Synoptic and quantitative attributions of the extreme precipitation leading to the August 2016 Louisiana flood, Geophysical Research Letters, 43, 1180511814, doi:10.1002/2016GL071460.

Wilks, D. S. (2006), On "field significance”, and the false discovery rate. Journal of Applied Meteorology and Climatology, 45, 1181-1189.

Wood, E.F., M. Sivapalan, and K. Beven (1990), Similarity and scale in catchment storm response, Reviews of Geophysics, 28, 1-18.
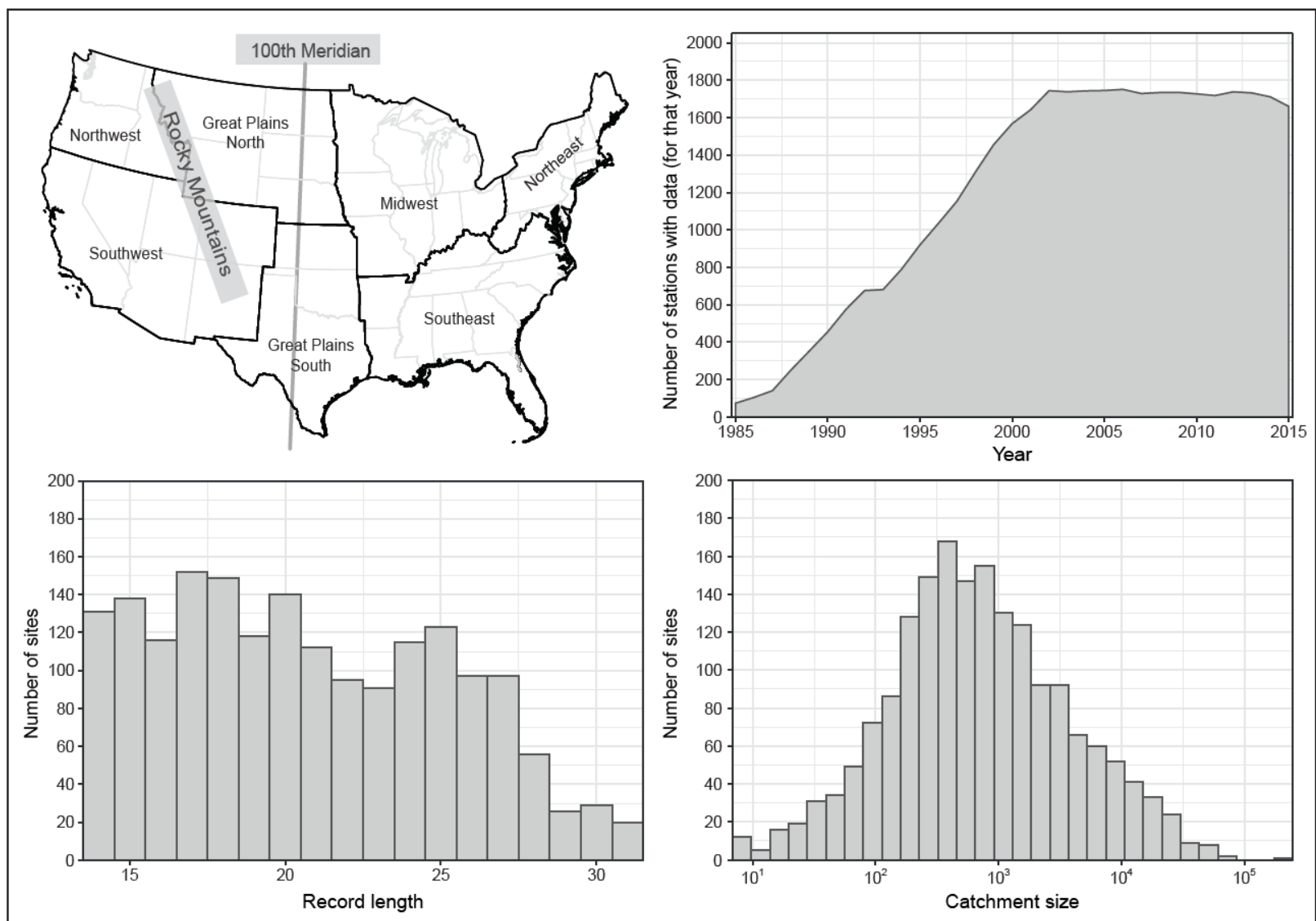

Figure 1: Descriptive statistics for the 1805 USGS sites considered in this study. Map indicating seven broad regions in the continental United States; Histograms showing the number of stations with data in every year, record length, and catchment size. 

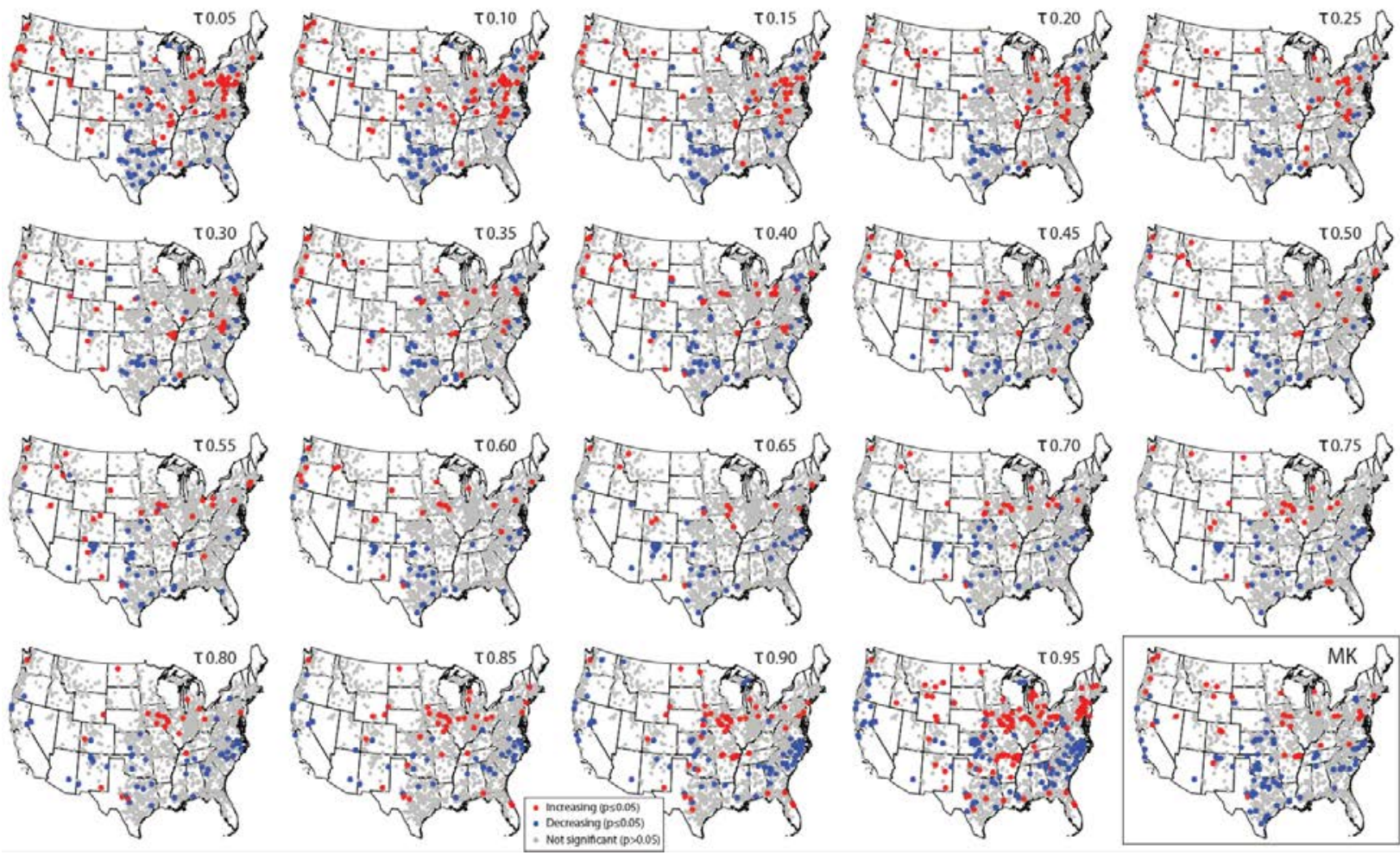

Figure 2: Temporal trends in flood stage at the 1805 USGS sites. The results are based on quantile regression ( $\tau$ from 0.05 to 0.95 with a step of 0.05 ) and the Mann-Kendall test (bottom298 right panel). The results are significant at the $5 \%$ level. 

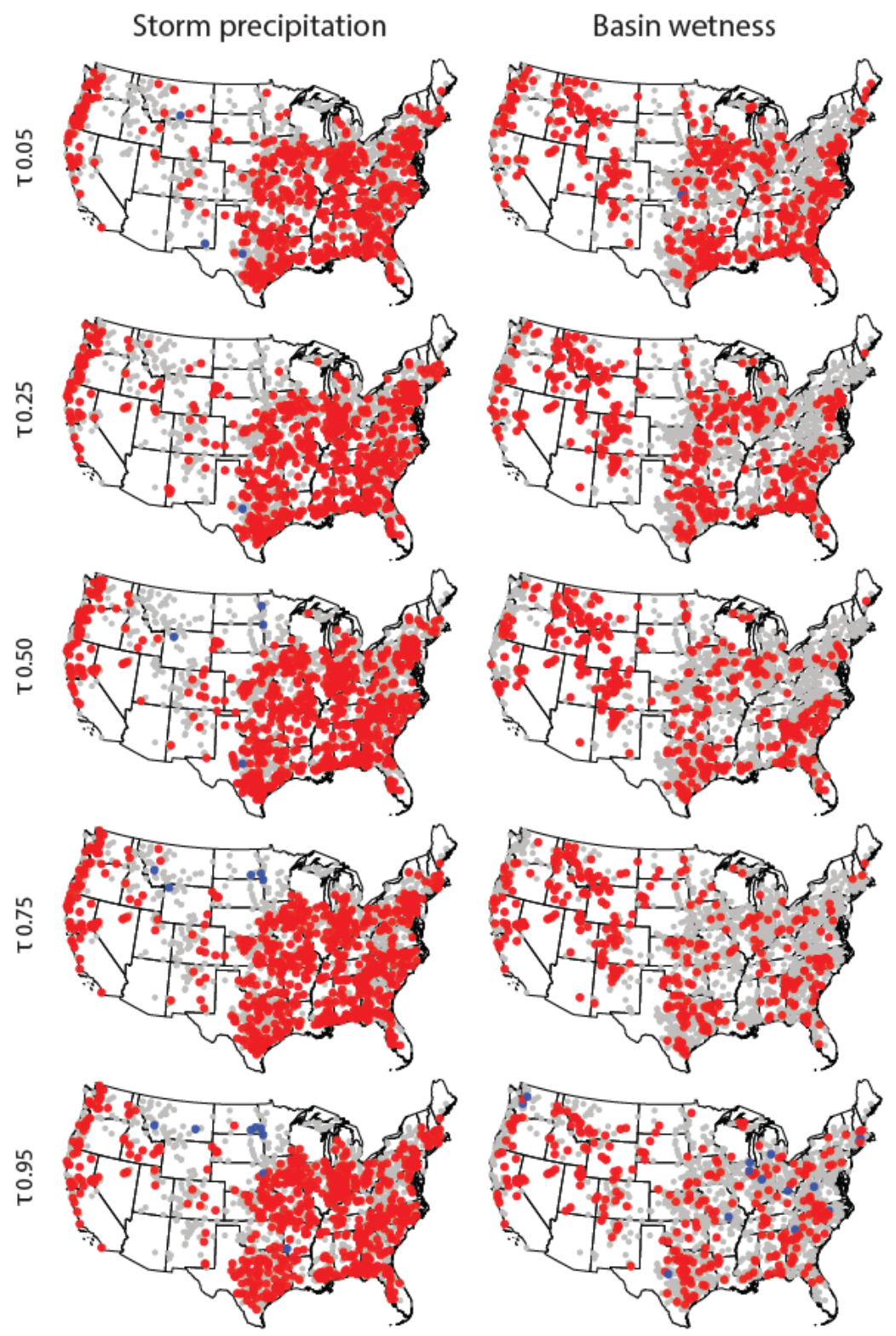

300 Figure 3: Maps showing the USGS stations for which storm precipitation (left panels) and basin wetness (right panels) are statistically significant predictors (at the $5 \%$ level). Rows indicate 302 different values of $\tau(0.05,0.25,0.50,0.75,0.95)$. 


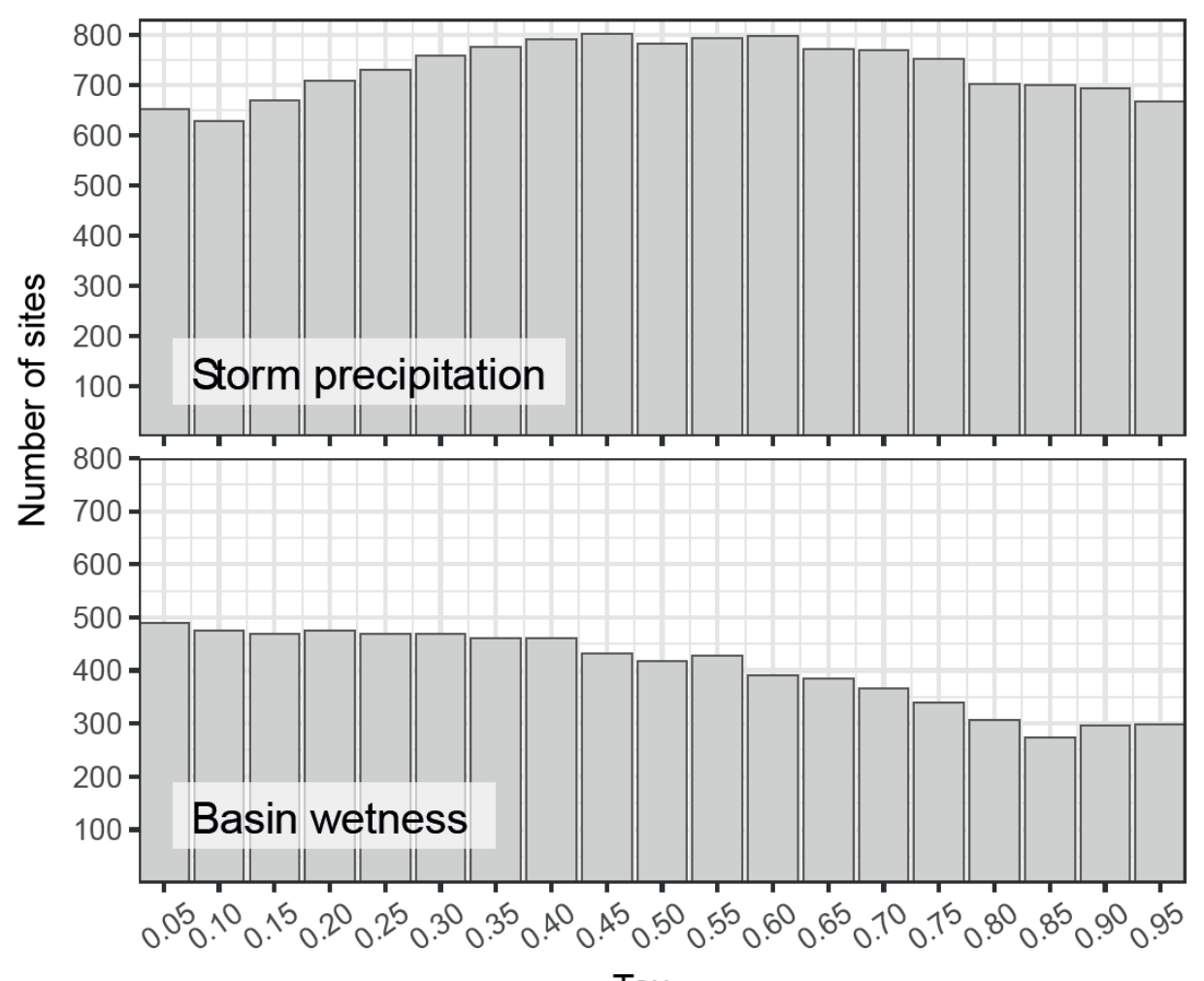

304 Figure 4: Histogram showing the number of sites for which storm precipitation (top panel) and 305 basin wetness (bottom panel) are positively and statistically significantly (at the $5 \%$ level) related to the gage height records for different $\tau$ values. 